\title{
ATÉ ONDE SÃO VÁLIDOS OS CONSENSOS?
}

Moraes-Filho JPP. Até onde são válidos os consensos? Arq Gastroenterol. 2010;47(2):128-9.

DESCRITORES - Conferência de consenso como assunto.

A busca cuidadosa na Internet revela uma quantidade extremamente elevada dos assim chamados "Consensos": Consenso Brasileiro de Diabetes, Consenso de Hipertensão Arterial, da Síndrome Metabólica, da Insuficiência Cardíaca, etc. São eles afinal tão importantes? Será que efetivamente constituem a última palavra em condutas? Podemos confiar literalmente nesses documentos?

Em primeiro lugar, vejamos o que se entende por "consenso". Segundo o Dicionário Houaiss é a concordância ou uniformidade de opiniões da maioria ou da totalidade de membros de uma coletividade. Até há alguns anos, as reuniões de consenso médico sobre diagnóstico e tratamento de enfermidades eram feitas por meio de votação sobre diferentes possibilidades de conduta. A opinião da maioria ou da totalidade dos participantes prevalecia como recomendação final. As opiniões dos consensualistas eram, no entanto, baseadas não só em dados da literatura muitas vezes inconsistentes, como também na experiência pessoal dos participantes. As propostas eram votadas e aceitas como resoluções. Foram nessas condições que tivemos em 2002, em São Paulo, o I Consenso da Doença do Refluxo Gastroesofágico (DRGE) ${ }^{(2)}$. Na ocasião, um grupo de especialistas, seguindo regras bem determinadas para expressão dos diferentes pareceres (em que $70 \%$ de concordância era considerada opinião de consenso), votou e publicou diretrizes de conduta sobre a enfermidade. Aquela forma de obtenção de consenso, contudo, não é mais aceitável. Hoje, a concordância deve ser baseada em evidências e o termo Diretrizes tem sido empregado. A mudança é certamente positiva mas, ainda assim, merece considerações.

É oportuno recordar os princípios da Medicina Baseada em Evidências e o que levou a sua criação. O numero crescente e surpreendentemente elevado de publicações científicas de qualidade discutível criou a necessidade de critérios que permitissem graduar a sua confiabilidade ${ }^{(5)}$. Trabalhos originais ou revisões sistemáticas com grau de recomendação A, por exemplo, são os que apresentam resultados de grande valor científico sobre investigação clínica em diagnóstico e/ou tratamento, considerando os ensaios clínicos randomizados com boa qualidade metodológica. Estes incluem número elevado de pacientes, procedimentos duplo-cegos, escolha aleatória de casos, utilização de placebo quando cabível, etc. Em outras palavras, são trabalhos que merecem muito crédito.
Pode-se concluir, portanto, que as recomendações de um consenso baseado em evidências, tal como o que foi recentemente publicado sobre a DRGE nos ARQUIVOS de GASTROENTEROLOGIA ${ }^{(4)}$, devem ser seguidas de forma absoluta, certo? Errado. A verdade é que, apesar de baseados em evidências, os consensos devem ser interpretados com certa cautela.

Inicialmente devemos considerar as condições em que os estudos clínicos que embasam os consensos/ diretrizes são realizados. Muitas vezes essas estão longe de representar as situações de vida real para as quais, precisamente, está sendo realizado o estudo. Com efeito, protocolos rigorosos de investigação clínica apresentam critérios estritos de inclusão e exclusão de pacientes. Estes devem ser cuidadosamente recrutados com queixas específicas e bem determinadas, tendo acompanhamento médico diferenciado durante a realização do projeto, favorecendo a ocorrência da desejável boa relação médico-paciente. Como se sabe, isso, entretanto, nem sempre corresponde à realidade da prática médica diária.

As comorbidades são geralmente excluídas do estudo o que, por si, pode constituir um expressivo viés de seleção. No Hospital das Clínicas de São Paulo, por exemplo, cerca de $50 \%$ dos pacientes com DRGE atendidos em ambulatório apresentam uma ou mais comorbidades $^{(3)}$. Dentre estas, as mais freqüentes são hipertensão arterial, hipercolesterolemia, obesidade, diabetes mellitus tipo II e depressão, precisamente aquelas enfermidades cuja prevalência aumenta com a idade, tal como ocorre com a própria DRGE. Como a medicação prescrita para as comorbidades desses pacientes poderia, eventualmente, interferir na resposta clínica da droga em estudo, tais pacientes devem ser excluídos dos estudos clínicos. Extrapolar os resultados desses trabalhos para o exercício diário da Medicina, em que muitos pacientes apresentam comorbidades pode, portanto, constituir importante fator de erro.

Outro aspecto importante que eventualmente limita a abrangência de estudos clínicos onde a dor é avaliada, é consequência da natureza subjetiva desta queixa que pode indicar tanto lesão orgânica como distúrbio funcional, ou ambos. Apesar da natureza orgânica e/ou funcional da dor, os estudos de investigação clínica não costumam contemplar relevância maior aos aspectos funcionais que podem estar por detrás das queixas. Na prática médica cabe ao clínico caracterizar quanto dos sintomas do paciente representa de orgânico e de 
funcional. No primeiro caso, trata-se de um aspecto objetivo, concreto, quantificável, enquanto o distúrbio funcional se compõe de um ou mais padrões subjetivos que são dificilmente quantificáveis. No caso dos estudos clínicos, os sintomas de natureza funcional que são muitas vezes relacionados à tensão, ansiedade, estresse e depressão ${ }^{(1)}$, não costumam ser devidamente considerados, limitando desse modo, mais uma vez, a confiabilidade dos resultados.

Em suma, os consensos são documentos válidos e constituem ferramenta importante na conduta para com nossos pacientes. Para algumas situações a orientação das diretrizes é plausível e aceitável, sem maiores questionamentos, como por exemplo a equivalência de diferentes posologias ou equivalência de tempos de tratamento. Em outras situações, entretanto, as conclusões merecem muita atenção e podem ser questionadas, como por exemplo, as comparações envolvendo qualidade de vida ou dor e seus equivalentes.

Os consensos/diretrizes compõem, pois, uma ordem geral que serve de guia ou de roteiro para as ações médicas. Deve ser lembrado, contudo, de que não constituem verdade absoluta e, por isso, precisam ser analisados criticamente em função de sua aplicabilidade frente a cada caso.

\section{Joaquim Prado P. MORAES-FILHO*}

Moraes-Filho JPP. How far are valid the consensus ? Arq Gastroenterol. 2010;47(2):128-9.

HEADINGS - Consensus development conference as topic.

\section{REFERÊNCIAS}

1. Ålander T, Svärdsudd K, Johansson SE, Agréus L. Psychological illness is commonly associated with functional gastrointestinal disorders and is important to consider during patient consultation: a population-based study. BMC Med 2005;3:8.

2. Moraes-Filho J, Cecconello I, Gama-Rodrigues J, Castro L, Henry MA, Meneghelli UG, Quigley E; Brazilian Consensus Group. Brazilian consensus on gastroesophageal reflux disease: proposals for assessment, classification and management. Am J Gastroenterol. 2002;97:241-8.
3. Moraes-Filho JP, Navarro-Rodriguez T, Eisig JN, Barbuti RC, Chinzon D, Quigley EM. Comorbidities are frequent in patients with gastroesophageal reflux disease in a tertiary health care hospital. Clinics (São Paulo). 2009;64:785-90.

4. Moraes-Filho JPP, Navarro-Rodriguez T, Barbuti R, Eisig J, Chinzon D, Bernardo W; Brazilian GERD Consensus Group. Brazilian consensus-guidelines for the diagnosis and management of the gastroesophageal reflux disease. An evidencebased consensus. Arq Gastroenterol. 2010;47:99-115.

5. The GRADE Working Group. Grading quality of evidence and strength of recommendations. BMJ 2004;328:1490-4.

* Departamento de Gastroenterologia, Faculdade de Medicina da Universidade de São Paulo, São Paulo, SP. 